\title{
Talking Tools to Assist Students Who are Blind in Laboratory Courses
}

\author{
Cary A. Supalo, Thomas E. Mallouk, Christeallia Amorosi, Lillian Rankel, H. David Wohlers, \\ Alan Roth, and Andrew Greenberg
}

\begin{abstract}
A number of tools and techniques have been developed to assist students with blindness and visual impairment who are studying in secondary and post-secondary science laboratories. Commercial electronic probes and their associated software packages allow real-time viewing and collection of data using a personal computer; however, until now, these data have been inaccessible to students with blindness or visual impairment because of the incompatibility of the data acquisition software with screen-reading software. Recent programming modifications now allow a new level of compatibility, which promotes a greater degree of independence and accessibility to laboratory science for people with visual impairments.
\end{abstract}

\section{BACKGROUND}

Authors' Note: We acknowledge that this work uses Job Access with Speech (JAWS) as the screen-reader of choice. This software was selected over other available text-tospeech screen-readers because of the flexibility of its scripting language, which allows customization for specific software applications. This work is being performed as a proof-of-concept study to develop a wider range of talking and audible tools, and is not intended to promote one screen-reader over another. We hope to expand our tool compatibility with other screen-reading programs after the tool development and implementation stages of this study have been completed.

Students who are blind or visually impaired (BVI) face a number of challenges in laboratory science courses. Because many observations and manipulations are visual in nature, it is often difficult for students with BVI to participate directly in the laboratory. Without special adaptive tools and techniques, they do not receive the educational benefit of the "hands on" science experience, nor are they on equal footing with their sighted peers. This problem has motivated the development of a number of computer-based assistive tools, and, most recently, talking laboratory tools.

There are many common misconceptions about safety issues for students who are BVI working in the science laboratory. A paper by Swanson and Steere (1981) discussed laboratory safety as pertaining to persons with disabilities (PWDs). In this work, a statistical comparison between employee safety records at DuPont of over 1450 employees with disabilities and non-disabled employees working in similar jobs under similar conditions was made. For the time period between 1958 and 1970, no additional safety risks were found for PWDs. This paper further documented that advanced planning and good organization were major reasons that PWDs held better safety records than their non-disabled counterparts.

In 1981, Lunney and Morrison used thencurrent technologies to adapt standard laboratory equipment to the needs of students with BVI. These authors posited a need for accessible tools, and felt that more active participation in school laboratory activities 
could lead to higher rates of retention in the areas of science, technology, engineering, and mathematics (STEM). Morrison and Lunney developed the first 3.5 digit multimeter, which was capable of speech output and could measure time, temperature, and $\mathrm{pH}$. They developed software that allowed students with BVI to use $\mathrm{pH}$ electrodes, visible spectrophotometers (Spectronic 20), infrared spectrophotometers, and piston burettes.

De Lucchi and Malone (1982) developed the Science Activities for the Visually Impaired (SAVI) curriculum. They detailed low-tech, relatively inexpensive laboratory adaptations for BVI students such as using notched syringes and triple beam balances for weight and volume measurements and a flexible plastic meter stick marked in Braille for measuring distances. The SAVI Selph curriculum also included a series of laboratory activities designed for the K-8 audience. It used non-hazardous materials and the instruments were made of plastic and other lightweight materials.

In 1983, Cetera described the use of two high-tech devices: a talking calculator from Sharp, which aided students with basic mathematical calculations, and the Opticon, a small camera able to read digital displays on balances and other laboratory equipment and then produce raised-line images from the data. Speech accessible computers were also discussed, and the paper predicted an increasing role of text-to-speech PCs in providing access to collected data.

A talking spectrophotometer was introduced by Hinchliffe and Skawinski, both from the New Jersey Institute of Technology, in 1983. In a move towards more accessible classrooms, the authors graciously provided, upon request, complete construction details of this device.

In 1984, Lunney and Morrison attempted to create a speech interface that could accommodate the use of still more probes. Known as the Universal Laboratory Training Research Aid (or ULTRA), the device served as an instructional aid and talking personal computer.

Shortly thereafter, Foulke and Taylor (1987) formulated a list of essential techniques that would enable students with BVI to measure masses, volumes, $\mathrm{pH}$, and other observable phenomena in a laboratory setting. Another notable innovation was the incorporation of a personal computer (the Apple IIe) into the data acquisition process.

Work by Wohlers and others in 1994 combined a now-unavailable speech-capable note taking device, the Braille 'N Speak, with standard laboratory equipment. In its "speech box mode," the note-taker was able to read aloud any data values received, via cable, from laboratory equipment capable of outputting ASCII data streams.

While many of the low-tech adaptive tools developed in the1980's and 1990's are still available or easily duplicated with inexpensive materials (most notably the SAVI tools), the computer-based tools have become outdated. Nevertheless, these early demonstrations provide solid examples of assistive technology for students who are BVI.

\section{VERNIER TOOLS AND LOGGER PRO}

High school curricula increasingly use personal computers in the data collection process. Logger Pro software from Vernier Software and Technology, created and 
designed with high school teachers and secondary-level students in mind, provides a software interface between laboratory probes and users. Vernier also publishes its own science curriculum and laboratory exercises for secondary students; the course developed by Volt and Sapatka (2000) covers the use of these probes in high school, and notes that the level of precision is sufficient for these target groups.

The Vernier Software and Technology company markets a line of over 70 low-cost analog and digital laboratory probes that allow a user to view, record, and manipulate data by using a personal computer. Up to four analog probes may be connected to the Vernier Lab Pro, a device that connects to a PC via USB port and potentially allows the parallel recording of four separate data streams. The computer program Logger Pro allows users to view data graphically, compare hypotheses, and conduct statistical analyses. While not precise enough for research or medical uses, these probes are priced low enough to maximize availability to their primary customer bases (high schoollevel laboratory classes). Vernier also produces a line of tools named $G o$, aimed at schools with exceptionally limited funding. When used in conjunction with a "Go-link" device, all the available probes plug directly into a USB port; data is then accessed with a scaled-down program named Logger Lite.

Job Access with Speech (JAWS) is another computer program frequently used by students who are BVI. JAWS is a computer screen-reader, typically able to speak the information that a sighted student would visually read. However, in an unmodified form, JAWS and Logger Pro are incompatible. Milchus and Goldwaithe wrote JAWS scripts for Logger Pro in 2000; although a level of success was achieved, the scripts were not maintained, and are now incompatible with newer versions of both JAWS and Logger Pro. To address this problem, new scripts have been written for current versions of Logger Pro (version 3.5) and JAWS (7.0 and 8.0), making the Vernier probes and data fully accessible to students with BVI. These scripts are available for download, free of charge, on the Independent Laboratory Access for the Blind (ILAB) website (see the figure below for installation instructions and the ILAB website [http://ilab.psu.edu] for necessary scripts).

Installation Instructions for Logger Pro 3.5 JAWS Scripts

\section{Unpack zipped script file on desktop or chosen location.}

\section{Open destination folder via JAWS} 7.0/Explore JAWS/Explore My Settings or JAWS 8.0.

3. Copy files into this folder. Compiling is unnecessary, as jsb files have been included for JAWS 7.0 and 8.0 in downloaded zip file.

*NOTE: The Ipreadme.htm file is currently the definitive reference for intended uses of the scripts with Logger Pro 3.5, as well as how one can use them with either JAWS 7.0 or 8.0. The document also includes a list of potential improvements for future JAWS scripts.

The scripts allow students who are blind or visually impaired to use Logger Pro with the Vernier probes in science experiments, collecting and analyzing a wide range of observational data with a greater degree of independence. Hot keys have been created for Logger Pro using the JAWS scripts to allow for navigation of the Logger Pro 
features (see the table below). In addition to speech output, JAWS can output the text stream to a refreshable Braille display, a device utilizing a matrix of pins representing Braille cells. These matrices appear in rows, displaying the characters of one line of text from the computer screen. Users can also determine which applications are running and which probes are currently functioning, as well as observe four probes, simultaneously, in real-time. Graphical data may also be sent to a Braille embosser and converted to raised-line format.

\begin{tabular}{|c|c|}
\hline \multicolumn{2}{|c|}{$\begin{array}{l}\text { JAWS/Logger Pro Hot Key Assignments } \\
\text { on Computer Keyboard }\end{array}$} \\
\hline $\begin{array}{l}{[\mathrm{CONTROL}]+} \\
{[\mathrm{SHIFT}]+[\mathrm{S}]}\end{array}$ & $\begin{array}{l}\text { Announces all } \\
\text { sensors on the status } \\
\text { bar sensor line }\end{array}$ \\
\hline $\begin{array}{l}{[\text { CONTROL }]+} \\
{[\text { SHIFT }]+[\text { probe }} \\
\text { number 1, 2, } \\
\text { 3...etc. }]\end{array}$ & $\begin{array}{l}\text { Announces real-time } \\
\text { probe reading based } \\
\text { on number- } \\
\text { designated probe } \\
\text { (found on sensor } \\
\text { line) }\end{array}$ \\
\hline $\begin{array}{l}\text { [CONTROL]+ } \\
{[\text { SHIFT }]+[\text { probe }} \\
\text { number twice } \\
\text { quickly] }\end{array}$ & $\begin{array}{l}\text { Allows user to set } \\
\text { time interval for } \\
\text { announcement } \\
\text { repetition }\end{array}$ \\
\hline [SPACE] & $\begin{array}{l}\text { Starts and stops data } \\
\text { collection }\end{array}$ \\
\hline $\begin{array}{l}{[\mathrm{CONTROL}]+} \\
{[\mathrm{SHIFT}]+[\mathrm{A}]}\end{array}$ & $\begin{array}{l}\text { Announces all } \\
\text { objects on computer } \\
\text { screen; once JAWS } \\
\text { announces "table," } \\
\text { press [ENTER] to } \\
\text { access collected data } \\
\text { values. } \\
\text { [CONTROL] + } \\
\text { [TAB] will then } \\
\text { announce } \\
\text { real-time readings }\end{array}$ \\
\hline
\end{tabular}

\section{MAINSTREAM CLASSROOM APPLICATIONS}

These modifications have now been successfully field-tested in mainstream chemistry classrooms. Students typically worked in pairs, although a few classes used groups of four. All students, sighted or BVI, used the same assemblage of soft- and hardware: a Lab Pro, interfaced with a PC equipped with Logger Pro 3.5 software. Temperature, $\mathrm{pH}$, voltage, and conductivity probes were made available, and each workspace was also equipped with a dropcounter digital probe, which allowed students to accurately control the rate at which one solution could be mixed with another. A brief example of a modified curriculum employing Vernier tools with JAWS in a physics experiment is detailed below:

"Back and Forth Motion," a physics experiment described in Vernier Physics with Computers (2003), uses a pendulum, inclined plane, ball, and a lab partner (jumping up and down) to study velocity, acceleration, and friction. Logger Pro software is required for data collection, and data is graphed using XY Cartesian graphs to show position and velocity as a function of time.

Modifications to this experiment consist of combining the Vernier motion sensor with $J A W S$ script files for access to real-time probe data values. Data collection, started and stopped by pressing the space bar, is performed by the Logger Pro software. Students with BVI navigate tables of motion sensor-collected data in each experiment; selected graphs are then exported to a Braille embosser set in "graphics mode" and reproduced as tactile graphs for each activity. The Audio Graphing Calculator (AGC), from View Plus Technologies, can also be utilized; it provides a changing audio pitch that 
mirrors the changing slope of the graph, with the $\mathrm{x}$-axis represented as time. Upon completion of the activity, students are expected to answer all questions, which deal with describing activities within the experiment, comparing velocity changes, and explaining differing velocities.

\section{SOCIETAL BENEFITS AND OUTCOMES}

Talking tools and adapted laboratory curricula are becoming more widely available for students who are blind or visually impaired and their educators for field-testing in classrooms across the country. These students now have access to the benefits of computer-based science in the form of Logger Pro software and JAWS, and may one day be able to choose their favorite screen-reader and combine that with other products that are similar to Logger Pro, such as Pasco and LabView. Once the proof-ofconcept phase of the ILAB project with Vernier hardware and software and the JAWS screen reader is completed, we will attempt to interface other screen-reader applications with Logger Pro. This will give students with BVI more choice in their methods of data acquisition, bringing a greater degree of accessibility and parity with sighted students.

Providing a greater number of audible and text-to-speech interface tools may derive additional benefits for students who have limited reading skills, are dyslexic, or have auditory processing deficits. As the speed of speech of these JAWS-combined probes can be changed according to a variety of needs, some audible tools may also be incorporated into lecture demonstrations to provide an additional channel of information, e.g., for students at the back of large lecture halls.
Persons with disabilities are experienced in solving problems related to accessibility over the course of their lives; thus, problemsolving skills are well-developed within this population. This quality imparts a great potential for this population to make significant intellectual contributions to the scientific community. The development and use of accessible laboratory equipment should increase the self-efficacy of students with BVI in laboratory science, and may ultimately increase their retention in the study of science, promoting their interest in subjects that are essential to career paths in the science, technology, engineering, and mathematics professions.

\section{ACKNOWLEDGMENTS}

This work was supported by the National Science Foundation through grant HRD0435656, and by the University of Wisconsin NSEC, NSF grant DMR-0425880.

\section{REFERENCES}

Appel, K., Gastineau, J., Bakken, C., \& Vernier, D. (2003). Physics with Computers. Vernier Software and Technology: Beaverton, OR.

Cetera, M. M. (1983). Laboratory adaptations for visually impaired students: thirty years in review. Journal of College Science Teaching, 12, 384-393.

De Lucchi, L. \& Malone, L. (1982). SAVI (Science Activities for the Visually Impaired). In S. Mangold (Ed.), A teacher's guide to the special educational needs of blind and visually handicapped children (pp. 72-93). American Foundation for the Blind; New York, NY. 
Hinchliffe, L. V. \& Skawinski, W. J. (1983). Hearing is believing: the modified spectroscope. Science Teacher, 50(4), 53-55.

Lunney, D., \& Morrison, R. (1981). High technology laboratory aids for visually handicapped chemistry students. Journal of Chemical Education, 58, 228-231.

Milchus, K., \& Goldwaithe, J. (2000). CSUN Conference Proceedings: using computers to make science lab accessible to students with disabilities. Retrieved October 2, 2007, from http://www.csun.edu/cod/conf/2000/proceedi ngs/csun00.htm.

Miner, D., Nieman, R., Swanson, A. B., Woods, M, \& Carpenter, K., Eds. (2001). Teaching Chemistry to Students with Disabilities: A Manual for High Schools, College, and Graduate Programs ( $4^{\text {th }} \mathrm{ed}$.). The American Chemical Society: Washington, DC.

Morrison, R., \& Lunney, D. (1984). The microcomputer as a laboratory aid for visually impaired science students. Journal of Visual Impairment and Blindness, 78, 41825.

Swanson, A.B., \& Steere, N. V. (1981). Safety considerations for physically handicapped individuals in the chemistry laboratory. Journal of Chemical Education, 58, 234-238.

Volt, D. \& Sapatka, S. (2000). Middle School Science with Calculators. Vernier Software \& Technology: Beaverton, OR.

Wohlers, H. D. (1994). Science education for students with disabilities. In EgelstonDodd, J. (Ed.), A future agenda: Proceedings of a working conference on science for persons with disabilities (52-64). University of Northern Iowa.

Woods, M. (1996) Working Chemists with Disabilities: Expanding Opportunities in Science ( $1^{\text {st }}$ ed.). American Chemical Society: Washington, DC.

\section{AUTHOR INFO}

\section{Cary A. Supalo}

Dept. of Chemistry

The Pennsylvania State University

casupal@ilstu.edu

\section{Thomas E. Mallouk}

Dept. of Chemistry

The Pennsylvania State University

tom@chem.psu.edu

\section{Christeallia Amorosi}

Dept. of Chemistry

The Pennsylvania State University

\section{Lillian A. Rankel}

Hopewell Valley Central High School

Pennington, NJ

\section{H. David Wohlers}

Dept. of Chemistry

Truman State University

\section{Alan Roth}

Indiana School for the Blind and Visually

Impaired

Indianapolis, IN

\section{Andrew Greenberg}

Dept. of Chemistry

University of Wisconsin at Madison 